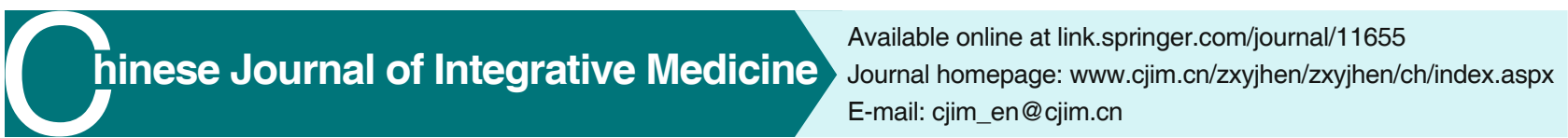

Original Article

\title{
Correlation Analysis of Rubella Incidence and Meteorological Variables Based on Chinese Medicine Theory of Yunqi*
}

\author{
ZHANG Xuan', MA Shi-lei², LIU Zhong-di', and HE Juan²
}

\begin{abstract}
Objective: To analyze the correlations between the incidence of rubella and meteorological factors over the same period and previous periods including 1, 2, 3 and 4 year ago (defined according to Chinese medicine Yunqi theory of "pestilence occurring after 3 years") and establish the rubella-meteorological forecast models for Beijing area, China. Methods: Data regarding the incidence of rubella between 1990 and 2004 from Beijing Center for Disease Control and Prevention, and the meteorological variables including daily average temperatures, daily average wind speeds, average precipitations, average relative humidity, average vapor pressures and average low cloud covers between 1986 and 2004 were collected from the Beijing Meteorological Observatory. Descriptive statistics and back-propagation artificial neural network for forecast model's establishment were adopted for data analysis. Results: The average temperature and relative humidity have a great contribution (100\%) to the rubella morbidity. But the combination of other meteorological factors contributed to improve the accuracy of rubella-meteorological forecast models. The forecast accuracy could be improved by $76 \%$ through utilizing a combination of meteorological variables spanning from 3 years ago to the present rather than utilizing data from a single year or dating back to more earlier time than 3 years. Conclusions: There is a close relationship between the incidence of rubella and meteorological variables in current year and previous 3 years. This finding suggests that rubella prediction would benefit from consideration to previous climate changes.
\end{abstract}

KEYWORDS rubella, meteorological factors, Chinese medicine, Yunqi theory, pestilence occurring after 3 years

Rubella is an acute viral infectious disease caused by rubella virus that is primarily transmitted by direct contact or respiratory transmission. Although the clinical symptoms and complications are mild and rare, rubella virus can cause severe or fatal consequences in pregnant women, even the fetuses, which include abortion, stillbirth or congenital rubella syndrome (CRS). It is estimated that there are 100,000 newborns with CRS each year worldwide. ${ }^{(1)}$ In China, rubella is defined as a category $C$ infectious disease. The data from Beijing Center for Disease Control and Prevention showed that 61,002 rubella cases were reported from 1990 to 2010 in Beijing area. Additionally, the morbidity of rubella ranged from 2.04 to 166.69 per 100,000 people, and the average annual morbidity was 24.04 per 100,000 people. Furthermore, the epidemic trend of rubella also has seasonal fluctuations, the peak prevalence usually occurs in April and May, which accounts for $76.18 \%$ of the total incidence. ${ }^{(2)}$

Most infectious diseases have seasonal patterns. ${ }^{(3)}$ The recognition of seasonal patterns in infectious disease has a long history, which can date back to Hippocratic era in Western medicine, or Huangdi's Internal Classic (Huang Di Nei Jing) era in Chinese medicine (CM). ${ }^{(4,5)}$ The small seasonal changes may be sufficient to create mass outbreak of disease, and the seasonal patterns can be influenced by climatic conditions, thus the study on seasonality is important for infectious disease research. ${ }^{(6)}$ In CM, the theory of Yunqi systematically discusses the effect of weather conditions on health and pathogenic conditions caused by abnormal changes. This

(C)The Chinese Journal of Integrated Traditional and Western Medicine Press and Springer-Verlag GmbH Germany, part of Springer Nature 2018

*Supported by the National Natural Science Foundation of China (No. 81072896), Young Scientists Fund of the National Natural Science Foundation of China (No. 81704198)

1. Chinese Clinical Trial Registry (Hong Kong), Hong Kong Chinese Medicine Clinical Study Centre, School of Chinese Medicine, Hong Kong Baptist University, Kowloon Tong, Hong Kong SAR, China; 2. School of Traditional Chinese Medicine, Beijing University of Chinese Medicine, Beijing (100029), China Correspondence to: Prof. HE Juan, Tel: 86-10-64287003, E-mail: hejuan6428@sina.com

DOI: https://doi.org/10.1007/s11655-018-3016-0 
doctrine is guided by the overall concept that human and nature correspond and have provided new ideas on infectious diseases research. By the Yunqi theory "pestilence occurring after 3 years", the prevalence of infectious disease is not only related to weather factors within the current year but also associated with meteorological factors that occurred 3 years ago. Some scholars found that the prevalence of severe acute respiratory syndrome (SARS) in 2003 in northern China was associated with the climate changes in 2000, which was characteristic of high temperature, less precipitation and a large area of arid climate. ${ }^{(7)}$ The practical value of "pestilence occurring after 3 years" received increasing more attention in recent years. $^{(8,9)}$

Since the meteorological variables may be the early indicators of outbreaks and epidemics, our study focuses on the association of rubella and meteorological variables of current year and particularly previous years. Based on the Yunqi theory, a forecasting model was developed using the previous data on rubella and meteorological variables.

\section{METHODS}

\section{Ethics Statement and Data Source}

The research involves no direct work with human subjects. The rubella case data were extracted from Beijing Center for Disease Control and Prevention. These reports were governmental documents that summarized the counts of patients who were diagnosed at health care facilities with a variety of diseases. All individual-level data were anonymous.

\section{Study Area}

Beijng, the capital city of China, $40^{\circ} \mathrm{N}$ and $116^{\circ} \mathrm{E}$, was selected as the study area. Many previous studies on Yunqi theory have been conducted using climate data of Beijing area. ${ }^{(10,11)}$ According to the Yunqi theory, the climatic characteristics are distinct during a year, and a CM concept called "six qi" mode describe this seasonal feature using the representative climate factor. $^{(12)}$

\section{Data Collection}

In this study, the meteorological are collected from the Beijing Meteorological Observatory from 1986 to 2004, including daily average temperature, daily average wind speed, daily precipitation, daily average relative humidity, daily average vapor pressure and daily average low cloud cover. The rubella data was collected from Beijing Center for Disease Control and Prevention from 1990 to 2004.

\section{Establishment of Database}

The statistical data for rubella and the meteorological factors are calculated using the concept of 'six qi'. ${ }^{(13-16)}$ The incidence of rubella in Beijing for each phase of the 'six qi' was calculated to establish a database from 1990 to 2003. The data in 2004 could not be calculated due to a lack of data about diseases in 2005. Similarly, the average values of 6 meteorological variables in Beijing for each phase of the 'six qi' from 1986 to 2003 were also calculated.

\section{Rubella-Meteorological Forecast Models Development}

Firstly, a descriptive statistic for meteorological factors and rubella morbidity were made to show the general regularities of weather and rubella prevalence during the past years. Secondly, the correlation between meteorological factors and rubella morbidity were analyzed by back-propagation artificial neural networks, a non-linear dynamic systems that belong to the class of feed-forward neural networks. ${ }^{(17-20)}$ In this study, the back-propagation artificial neural networks methods were used to assess the importance of various meteorological factors of previous years and the current year on the outbreak of rubella. The meteorological factors with impact degrees (i.e. the standardized significance by model calculations) above $50 \%$ were selected as important variables related to the incidence of rubella. Thirdly, the rubellameteorological forecast models were established and assessed. Specifically, a total of 8 rubella-meteorological forecast models for the prediction of the prevalence of rubella, as presented in Table 1, were established by back-propagation artificial neural networks, and the forecasting accuracy was compared. The 8 models were divided into two groups, including Group 1 (e.g. models 1-4) analyzed rubella morbidity and meteorological factors of a single year; and Group 2 (e.g. models 5-8) analyzed rubella morbidity and combined meteorological factors of previous years. All of the samples were divided into training samples and testing samples to prevent over fitting. An ideal network model could be achieved when the test samples are less than the training samples. Consequently, the data for training and forecasting were randomly selected at the default ratio of $7: 3$ 
that was the most commonly used in the statistical analysis. The criteria of successful model assessment are according to the relative error values of training and testing, which should be less than 1 , and the model will be considered to be successfully created. ${ }^{(21)}$

Table 1. Rubella-Meteorological Forecast Models

\begin{tabular}{|c|c|c|c|}
\hline Model & Year & $\begin{array}{l}\text { Meteorological factors } \\
\text { (Input variables) }\end{array}$ & $\begin{array}{l}\text { Rubella incidence } \\
\text { (output variables) }\end{array}$ \\
\hline \multicolumn{4}{|l|}{ Group 1} \\
\hline Model 1 & Y0 & Data Set 1 & 1990-2003 \\
\hline Model 2 & Y1 & Data Set 2 & 1990-2003 \\
\hline Model 3 & Y2 & Data Set 3 & 1990-2003 \\
\hline Model 4 & Y3 & Data Set 4 & 1990-2003 \\
\hline \multicolumn{4}{|l|}{ Group 2} \\
\hline Model 5 & $Y 0+Y 1$ & Data Set $1+$ Data Set 2 & 1990-2003 \\
\hline Model 6 & $Y 0+Y 1+Y 2$ & $\begin{array}{l}\text { Data Set } 1 \text { + Data Set } 2+ \\
\text { Data Set } 3\end{array}$ & 1990-2003 \\
\hline Model 7 & $\mathrm{Y} 0+\mathrm{Y} 1+\mathrm{Y} 2+\mathrm{Y} 3$ & $\begin{array}{l}\text { Data Set } 1 \text { + Data Set } 2+ \\
\text { Data Set } 3 \text { + Data Set } 4\end{array}$ & 1990-2003 \\
\hline Model 8 & $\mathrm{Y} 0+\mathrm{Y} 1+\mathrm{Y} 2+\mathrm{Y} 3+\mathrm{Y} 4$ & $\begin{array}{l}\text { Data Set } 1+\text { Data Set } 2+ \\
\text { Data Set } 3+\text { Data Set } 4+ \\
\text { Data Set } 5\end{array}$ & 1990-2003 \\
\hline
\end{tabular}

Notes: Y0: current year; $Y 1: 1$ year ago; $Y 2: 2$ years ago; $Y 3: 3$ years ago; Y4: 4 years ago; Data Set 1: 1990-2003; Data Set 2: 1989-2002; Data Set 3: 1988-2001; Data Set 4: 1987-2000; Data Set 5: 1986-1999

\section{Statistical Analysis}

Among the successful models, the one with highest accuracy was selected. All analyses were conducted with SPSS version 17.0 (FTP://202.204.41.200, www.bucm.edu.cn).

\section{RESULTS}

\section{Descriptive Analysis}

A summary of the meteorological data counted by "six qi" phase from 1987 to 2003 is presented in Table 2. The peaks of average temperature, average precipitation, average vapor pressure and average low cloud cover appeared in the 3rd qi (i.e. June and July). In comparison, the low points of these variables appeared in the 6th qi (i.e., December and January of the next year) and the average low cloud cover has a minimum in the 1st qi (i.e., February and March). Additionally, the peak of average relative humidity appeared in the 4th qi (i.e., August and September) and low point appeared in the 1st qi. In contrast, the peak of average wind speed appeared in the 2nd qi (i.e., April and May) and low point occurred in the 4 th qi.

In Beijing area, 54,186 cases of rubella were reported from January 1990 to January 2004. As
Table 2. Average Value of Meteorological Variables in Each 'Six Qi' from 1987 to 2003

\begin{tabular}{lcccccc}
\hline $\begin{array}{l}\text { Meteorological } \\
\text { variables }\end{array}$ & 1st qi & 2nd qi & 3rd qi & 4th qi & 5th qi & 6th qi \\
\hline $\begin{array}{l}\text { Daily average } \\
\text { temperature }\left({ }^{\circ} \mathrm{C}\right)\end{array}$ & 4.70 & 18.55 & 25.97 & 21.92 & 7.52 & -2.00 \\
$\begin{array}{l}\text { Daily average wind } \\
\text { speed (m/s) }\end{array}$ & 2.65 & 2.78 & 2.16 & 1.99 & 2.16 & 2.32 \\
$\begin{array}{l}\text { Daily average } \\
\text { precipitation (mm) }\end{array}$ & 0.28 & 1.09 & 4.60 & 2.27 & 0.49 & 0.09 \\
$\begin{array}{l}\text { Daily average } \\
\text { relative humidity (\%) }\end{array}$ & 43.60 & 49.40 & 67.90 & 68.90 & 55.90 & 45.80 \\
$\begin{array}{l}\text { Daily average vapor } \\
\text { pressure (Hpa) }\end{array}$ & 3.70 & 10.47 & 22.20 & 18.28 & 6.10 & 2.38 \\
$\begin{array}{l}\text { Daily average low } \\
\text { cloud cover (\%) }\end{array}$ & 1.00 & 2.00 & 4.00 & 3.00 & 2.00 & 1.00 \\
\hline
\end{tabular}

indicated in Figure 1, the rubella morbidity showed an obvious seasonality with the highest prevalence in the 2 nd qi, accounting for $57 \%$ of the average annual incidence of rubella. Comparatively, rubella was in a state of low prevalence during the 4th, 5th, 6th and 1 st qi, which accounted for $1.7 \%, 0.8 \%, 3.8 \%$ and $11.0 \%$ of the average annual incidence of rubella, respectively.

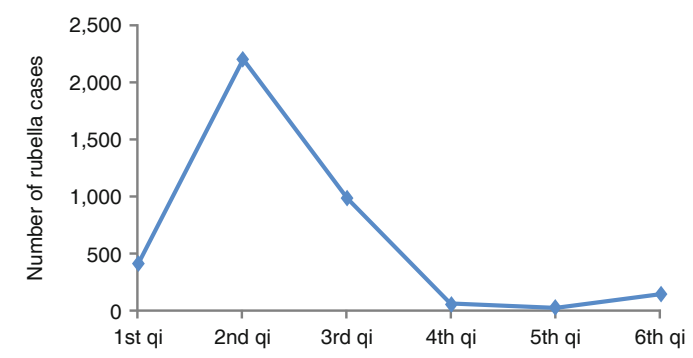

Figure 1. Seasonal Pattern of Rubella Incidence in Six Qi from 1990 to 2003

Rubella-Meteorological Forecast Model Development Based on Back Propagation Artificial Neural Network

Group 1: Rubella Morbidity and Meteorological Factors of Single Year

As presented in Table 3, all 4 prediction models (Models 1-4) were successful established, while the prediction accuracy were lower than $30 \%$. In addition, several meteorological factors from different year periods had significant influences on the incidence of rubella, including average temperature, average relative humidity and average precipitation from the current year, average relative humidity, average temperature and average low cloud cover from 1 year ago; average temperature, average relative humidity, average low cloud cover and average wind speed from 2 years ago; and average precipitation and 
Table 3. Summary of the Results of the Rubella-Meteorological Forecast Models

\begin{tabular}{|c|c|c|c|c|c|}
\hline \multirow[b]{2}{*}{ Item } & \multicolumn{2}{|c|}{ Training } & \multicolumn{2}{|c|}{ Test } & \multirow{2}{*}{$\begin{array}{c}\text { Mean } \\
\text { prediction } \\
\text { accuracy }(\%)\end{array}$} \\
\hline & $\begin{array}{c}\text { Relative } \\
\text { error }\end{array}$ & $\begin{array}{c}\text { Prediction } \\
\text { accuracy } \\
(\%)\end{array}$ & $\begin{array}{c}\text { Relative } \\
\text { error }\end{array}$ & $\begin{array}{c}\text { Prediction } \\
\text { accuracy } \\
(\%)\end{array}$ & \\
\hline \multicolumn{6}{|l|}{ Group 1} \\
\hline Model 1 & 0.687 & 31 & 0.792 & 21 & 26 \\
\hline Model 2 & 0.868 & 13 & 0.772 & 23 & 18 \\
\hline Model 3 & 0.701 & 30 & 0.804 & 20 & 25 \\
\hline Model 4 & 0.851 & 15 & 0.777 & 22 & 19 \\
\hline \multicolumn{6}{|l|}{ Group 2} \\
\hline Model 5 & 0.714 & 29 & 0.824 & 18 & 24 \\
\hline Model 6 & 0.489 & 51 & 0.433 & 57 & 54 \\
\hline Model 7 & 0.177 & 82 & 0.305 & 70 & 76 \\
\hline Model 8 & 0.750 & 53 & 0.480 & 52 & 53 \\
\hline
\end{tabular}

Notes: Model 1: current year; Model 2: 1 year ago; Model 3: 2 years ago; Model 4: 3 years ago; Model $5: 1$ year ago to the present; Model 6: 2 years ago to the present; Model 7: 3 years ago to the present; Model 8: 4 years ago to the present

average low cloud cover from 3 years ago. Of them, the largest contribution (100\%) factors included average temperature from the current year and 2 years ago, average relative humidity from 1 year ago, and average precipitation from 3 years ago (Table 4).

\section{Group 2: Rubella Morbidity and Combined Meteorological Factors of Previous Years}

As presented in Table 3, Models 5 to 8 (Group 2) were successful established and the prediction accuracy of these models were higher than those in Models 1 to 4 (Group 1). The highest forecast accuracy appeared in Model 7 (76\%), which used the meteorological factors from current year to 3 years ago. However, when data from 4 years ago were added to create Model 8 , the prediction accuracy was reduced. Thus, there was no need to consider the meteorological factors of earlier periods than 3 years ago. Additionally, there were many meteorological factors from different year combinations, which presented influences above $50 \%$ on the incidence of rubella. Among them, the largest contribution (100\%) factors were average temperature and average relative humidity from the current year, and average wind speed from 2 years ago (Table 4).

\section{DISCUSSION}

Based on the CM Yunqi theory, this retrospective study analyzed the correlations between the rubella morbidity and meteorological factors in Beijing area.
Table 4. Important Meteorological Factors of Rubella-Meteorological Forecast Models

\begin{tabular}{ll}
\hline Model & $\begin{array}{l}\text { Meteorological factors (standardized significance } \\
>50 \%, \text { in descending order) }\end{array}$ \\
\hline Model 1 & $\begin{array}{l}\text { Average temperature (100\%), average relative } \\
\text { humidity }(93.7 \%) \text { and average precipitation }(55.7 \%) \\
\text { in current year }\end{array}$
\end{tabular}

Model 2 Average relative humidity (100\%), average temperature $(90.5 \%)$ and average low cloud cover $(75.2 \%)$ in 1 year ago

Model 3 Average temperature (100\%), average relative humidity $(67.9 \%)$, average low cloud cover $(66.4 \%)$ and average wind speed $(52.4 \%)$ in 2 years ago

Model 4 Average precipitation (100\%) and average low cloud cover $(62.5 \%)$ in 3 years ago

Model 5 Average temperature $(100 \%)$ in current year, average relative humidity $(92.9 \%)$ in 1 year ago, average relative humidity $(83.7 \%)$ in current year, and average low cloud cover $(50.4 \%) 1$ year ago

Model 6 Average wind speed (100\%) in 2 years ago, average relative humidity $(99.0 \%)$ in current year and average temperature $(80.1 \%)$ in 2 years ago

Model 7 Average relative humidity (100\%) in current year, average wind speed $(85.6 \%)$ in 2 years ago, average low cloud cover $(70.8 \%)$ in 3 years ago, and average temperature $(57.8 \%)$ in current year

By using back propagation artificial neural network, several rubella-meteorological forecasting models were established, which were characterized by the time spans ranging from the current year to 3 years ago, and the vital meteorological factors on the incidence of rubella were selected. The study focused on the impact of meteorological variables over the same period and previous periods on the incidence of rubella.

The doctrine 'pestilence occurring after 3 years' was found in the Huangdi's Internal Classic which is the source of $\mathrm{CM}$ theory. It contributed noteworthy observations about the influence of abrupt climatic changes or unusual weather conditions from 1 to 3 years ago on the present incidence of various infectious diseases.

Consequently, we found that the prediction accuracies of rubella-meteorological models in Group One, which used the data of rubella morbidity and meteorological factors of single year, were undesirable. However, the prediction accuracies of rubellameteorological models in Group 2, which used the data of rubella morbidity and combined meteorological factors of previous years, were obviously improved compared with Group 1. With the addition of more 
meteorological data coming from previous years, the prediction accuracy showed a rising trend, reaching the top accuracy $(76 \%)$ when the meteorological data within previous 4 years were combined (current year +1 year ago +2 years ago +3 years ago). Then a downward trend appear if more data of previous meteorological data (current year +1 year ago +2 years ago +3 years ago +4 years ago) were added. Thus, there is no need to use the data of earlier periods than 3 years, which prove the doctrine of Yunqi theory "pestilence occurring after 3 years".

We also found that average temperature and average relative humidity, especially in the current year, were selected as vital meteorological factors because they made the largest contributions to the rubella-meteorological forecasting models, as indicated in the back propagation artificial neural network analysis. This suggests that the conditions of temperature and humidity in Beijing area are significantly related to the outbreak of rubella. However, if considering other meteorological factors in 1-3 years ago, the prediction results of rubellameteorological forecasting models would be greatly improved. Thus, the rubella prevention and control will benefit from considering the local previous climate changes, which consistent with the findings of other studies in infectious diseases. ${ }^{(22-24)}$

The innovations of this study are summarized as follows. Firstly, based on the CM theory of Yunqi, this study divided one year into 6 equal periods ( 4 solar terms per period) that are called the 'six qi' or 'six phases' to describe the seasonal variations in the rubella incidence and meteorological variables. Secondly, this study focused on the effects of previous changes of weather that occurred in the past 3 years on the present incidence of rubella, which could improve the timeliness of forecasts based on established early warning models. Thirdly, back propagation artificial neural network was introduced to select the most significant weather indicator and establish the rubella-meteorological predictive models. Fourthly, this study selected a good model by analyzing and comparing each of the models.

This study also has some limitations. Although meteorological variables were used to identify possible causal factors for the incidence of rubella in Beijing area, the outbreak of rubella is a complex course affected by multiple factors. Some other important issues should be considered, such as biological, sociological, and economical factors.

Taken together, this study provides a quantitative evidence that the incidence of rubella in Beijing area was associated with meteorological variables, such as temperature and relative humidity, in the corresponding and previous years. Moreover, the rubella-meteorological forecast model from the perspective of 3 years ago to the present was successfully established and presented a relatively high accuracy rate, which suggested the use of a combination of meteorological factors spanning from 3 years ago is superior to the use of data from a single. And there is no need to use the data of earlier periods. This information could be helpful in the early prediction of rubella outbreaks and build public health prevention and intervention strategies. Therefore, some guiding ideology on Yunqi theory regarding "pestilence occurring after 3 years" in CM may be beneficial to provide new ideas for the research of using climate to predict outbreaks of infectious diseases, such as rubella. Also, similar studies in other geographical areas and over longer time periods are needed to better understand the impact of weather variables on rubella.

\section{Conflict of Interest}

The authors declare no competing interests.

\section{Author Contributions}

Zhang $X$ analyzed the data and wrote the manuscript. Ma $S L$ revised the manuscript. Liu ZD collected and checked the data. He $\mathrm{J}$ conceived and designed the experiments. All authors have read and approved the contents of the final version.

\section{Acknowledgment}

We would like to thank the Beijing Meteorological Observatory for collecting the meteorological data and the Beijing Center for Disease Control and Prevention for the data related to the incidence of rubella.

\section{REFERENCES}

1. Robertson SE, Featherstone DA, Gacic-Dobo M, Hersh BS. Rubella and congenital rubella syndrome: global update. Rev Panam Salud Publica 2003;23:306-315.

2. Liu DL, Chen M, Lu L, Wu J. Epidemiological analysis of rubella in Beijing, 1990-2010. Chin J Epidemiol (Chin) 2011;32:949-950. 
3. Canals M. Seasonal pattern of infectious disease: similarity and differences. Rev Med Chil 1997;126:403-408.

4. Falagas ME, Bliziotis IA, Kosmidis J, Daikos GK. Unusual climatic conditions and infectious diseases: observations made by Hippocrates. Enferm Infecc Mircobiol Clin 2010;28:716-718.

5. Wang HT, He J, eds. Vernacular solution of 'Plain Questions of the Huangdi's Canon of Medicine'. Beijing: People's Medical Publishing House; 2014:2.

6. Fisman DN. Seasonality of infectious diseases. Annu Rev Public Health 2007;28:127-143.

7. Gu ZS. Discussion of severe acute respiratory syndromes (SARS) from perspective of Yunqi theory. Chin J Basic Med Tradit Chin Med (Chin) 2003;9:1-3.

8. Gu ZS. Recognition of generations of doctors on reasons of epidemic disease. J Zhejiang Univ Tradit Chin Med (Chin) 2009;54:648-649.

9. Liu ZD, Zhang X, He J. Based on the theory of 'transformation of plague in three years' to explore the correlation between incidence of dysentery and climate changes. Chin J Tradit Chin Med Pharm (Chin) 2013;33:1427-1430.

10. Liu YQ, Gao SH, Zhang DS, He J, Ding Y, Ma XM. On WANG Bing's mistake in calculation model for annotating Yunqi (five circuits and six qi) based on Beijing meteorological data for 60 years. J Beijing Univ Tradit Chin Med (Chin) 2010;42:813-816.

11. Ding Y, Gao SH, Zhang DS, Li HT, He J. Analysis of climatic characteristic of dominant yun in Beijing for 60 years. J Tradit Chin Med (Chin) 2011;31:910-911.

12. Zhang DS, Gao SH, Li HT, Ding Y. Analysis of climate changes in Beijing based on the six qi theory of Chinese medicine. Chin Med Res (Chin) 2010;9:1-2.

13. Zhang DS, He J, Gao SH, Hu BK, Zhang AY, Li HT, et al. Analysis of climate characteristics of 24 solar terms in Beijing. J Tradit Chin Med (Chin) 2010;S2:35-36.

14. Zhang DS, He J, Gao SH, Hu BK, Ma SL. Correlation analysis for the attack of respiratory diseases and meteorological factors. Chin J Integr Med 2011;17:600-606.
15. Tang QL, Fu BZ, Huang L, Gao SH, He J. Correlation between attack of bacillary dysentery and six qi or meteorological factors in Beijing. J Tradit Chin Med (Chin) 2013;33:570-572.

16. Liu ZD, Zhang X, He J. Coincidence between Yun-qi of the heavenly stems and earthly branches and actual climatic changes in Beijing for 60 years. J Beijing Univ Tradit Chin Med (Chin) 2013;45:529-533.

17. Wu XY, Wang TF, Zhao Y, Yu CG, Li ZG, Wang QG. Exploration of the use of mathematical methods in the syndrome analysis research. Jiangsu J Tradit Chin Med (Chin) 2007;39:53-55.

18. Sun ZQ, ed. Medical statistics. Beijing: People's Health Publishing Press; 2007:478.

19. Ma SL, Tang QL, Liu HW, Gao SH, He J. Correlation analysis for the attack of bacillary dysentery and meteorological factors based on the Chinese medicine theory of Yunqi and the medical-meteorological forecast model. Chin J Integr Med 2013;19:182-186.

20. Hu JY, Jiang MJ, Jing YS, Wan BC, Liu C. Application of neural network in forecasting tuberculosis caused by meteorological factors. Bull Sci Technol (Chin) 2013;29:19-23.

21. Zhang WT, Zhong YF, eds. Case pristine in data analysis and mining of IBM SPSS. Beijing: Tsinghua University Press; 2013:128.

22. Liu ZD, Zhang X, He J. Relationship between meteorological factors and incidence of dysentery in Beijing area based on theory of 'pestilence occurring after three years'. J Beijing Univ Tradit Chin Med (Chin) 2013;45:258-262.

23. Zhang X, Zulihumaer A, Liu ZD, Ma SL, He J. Correlation between typhoid/paratyphoid and meteorological factors and establishment of forecast model based on theory of five circuits and six qi. J Beijing Univ Tradit Chin Med (Chin) 2013;45:797-801.

24. Zhang $X, \mathrm{He}$ J. Correlation between meteorological factors and mumps incidence in Beijing from 1990 to 2004. Chin J Tradit Chin Med Pharm (Chin) 2014;29:1740-1745. (Accepted March 9, 2016; First Online November 22, 2018) Edited by TIAN Lin 